\title{
Fuzzy State Space Model for a Pressurizer In a Nuclear Power Plant
}

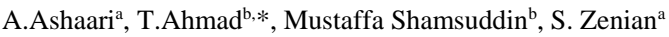 \\ ${ }^{a}$ Department of Mathematical Science, Faculty of Science, 81310 UTM Johor Bahru, Johor, Malaysia. \\ ${ }^{b}$ Institute of Ibnu Sina, Nanotechnology Research Alliance, Universiti Teknologi Malaysia, 81310 UTM Johor Bahru, Johor, Malaysia \\ *Corresponding Author: tahir@ibnusina.utm.my
}

\section{Article history :}

Received 25 Sept 2014

Accepted 7Apr 2015

GRAPHICAL ABSTRACT

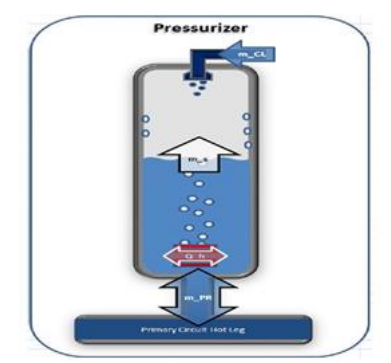

\begin{abstract}
In this paper, Fuzzy State Space Model (FSSM) for a nuclear power plant is proposed. Pressurizer is used to control pressure and temperature in a nuclear power plant. In order to maintain the pressure and the temperature of the system, the effectiveness of the system needs to be monitored frequently. Hence, fuzzy state space approach is used to model the pressurizer. The influence of input to output of the pressurizer is established and presented in this paper. The result from the model is then verified against published data.
\end{abstract}

Keywords: Nuclear power plant, Pressurizer, Fuzzy state space

(C) 2015 Penerbit UTM Press. All rights reserved http://dx.doi.org/10.11113/ mjfas.v11n2.336

\section{INTRODUCTION}

Nuclear power plants are one of the most frequently mentioned areas for thermal energy. Our interest is the pressurizer system of a combined cycle power plant, which is used in maintain the system pressure within the specified limits. The analysis of such system is often very complicated. The characterizing equations are generally is a set of partial differential equations, with nonlinearity arising due to convection of momentum in the flow, variable properties and radioactive transport [1]. However, approximation and idealizations are used to simplify these equations, resulting in algebraic and ordinary differential equations for many practical situations. Thus, it is assumed that the system can be represented by a lumpedparameter model.

A Pressurizer consist of two main functions in primary circuit, namely to maintain the pressure within the specified limits and to control the coolant mass flow in the primary circuit. The pressure is controlled either by increasing the amount of bubble in pressurizer through heating or increasing the steam condensation through water spray (see Figure 1). The spray water is extracted from the reactor coolant cold piping of the main coolant pump.

If a reactor coolant system temperature is increased, then the density of the reactor coolant will be decreased. It will cause the water to take up substantial space in pressurizer. When the level of water increase, then the steam in top of pressurizer is compressed. Hence, the pressure is increased [2].

However, if the reactor coolant temperature decreased, then the water will become denser and occupy less space. The water level in pressurizer will decrease which cause the pressure to be decreased.

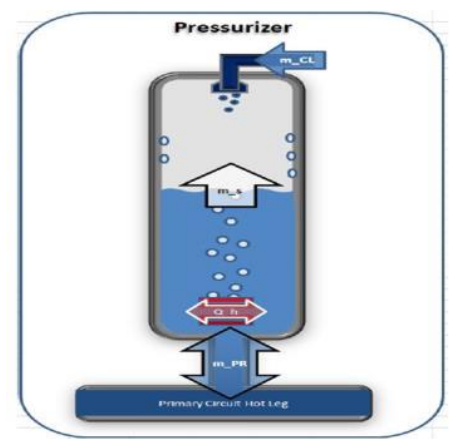

Figure. 1 Pressurizer

If the pressure started to increase above the specified limit, then the cold water from the reactor coolant pump will be sprayed into the steam space in pressurizer. It will cause the water to condense from steam into water and reduce the pressure. However, if the pressure continuous to increase, the relief valves will open to release the steam to pressurizer relief tank. If the pressure 
starts to decrease, the electrical heaters are used to boil the water.

\section{MODEL EQUATIONS}

There are some assumptions that are made in order to have a low order dynamic model of the pressurizer [3]:

a) The mass change caused by the phase transitions is neglected.

b) The mechanical work effect is also neglected.

c) The steam is in saturated state.

d) The rising bubbles in the water region escape at saturation state.

e) The droplets raining out from the steam and fluids condensing on the wall reach the saturation state before entering the water region.

f) The two regions share the same pressure that belongs to the saturated state of the steam.

g) The pressure dependence of the thermo dynamical variable (e.g. enthalpy, density) is neglected.

h) The mass change in the pressurizer is caused by the temperature change of the primary circuit coolant, the feed water and the surge.

The wall condensation, bubble rising and heat transfer are essential elements of mass and energy transfer. These justify that the energy transfer attached to the surges is neglected. Energy balance is constructed for the liquid [3]. The pressurizer considered the mass in/out flow from the primary circuit $M_{P R}$, the heat loss $W_{l o s s, P R}$ and the heating $W_{\text {heaty, } P R}$. The mass conservation for each of the balance volumes are as follows:

$\frac{d M_{w, P R}}{d t}=m_{P R}-m_{s, P R}$

$\frac{d M_{S, P R}}{d t}=m_{s, P R}$

Such that $M_{P C}$ is the mass of water for primary circuit, $m_{i n}$ is the inlet mass flow rate, and $m_{\text {out }}$ is the purge mass flow rate of the primary circuit. By assumption in (a), the term $m_{S, P R}$ is neglected in the mass balance equations. The new mass conservation is [4]:

$\frac{d M_{P R}}{d t}=m_{P R}$

$\frac{d M_{P C}}{d t}=\left(m_{\text {in }}-m_{\text {out }}\right)-M_{P R}$

$$
\begin{aligned}
\frac{d T_{P R}}{d t}=\frac{1}{c_{p, P R} M_{P R}} & \left(X_{m_{P R}>0} c_{p, P C} M_{P R} T_{P C}\right. \\
& +X_{m_{P R}>0} c_{p, P R} M_{P R} T_{P R} \\
& -c_{p, P R} M_{P R} T_{P R}-W_{\text {loss }, P R} \\
& \left.+W_{\text {heaty }, P R}\right)
\end{aligned}
$$

and

$$
\begin{aligned}
& m_{P R}= \\
& \frac{\left(m_{\text {in }}-m_{o u t}\right) M_{p c}-V_{p C}^{0} c_{\varphi, 1}\left(m_{\text {in }} T_{p c, I}-m_{o u t}\right)}{M_{p c}} \\
& -\frac{V_{p C}^{0} c_{\varphi, 1}\left(c \psi+6 K_{T, S G} T_{S G}-W_{\text {loss }, p c}\right)}{c_{p, p c} M_{p c}} \\
& +\left(\begin{array}{c}
\frac{V_{p C}^{0} c_{\varphi, 1}\left(c_{p, p c} m_{i n}+6 K_{T, S G}\right)}{c_{p, p c} M_{p c}} \\
-\frac{2 V_{p C}^{0} c_{\varphi, 2}\left(m_{i n} T_{p c, I}-m_{o u t}\right)}{M_{p c}} \\
-\frac{2 V_{p C}^{0} c_{\varphi, 2}\left(c \psi+6 K_{T, S G} T_{S G}-W_{l o s s, p c}\right)}{c_{p, p c} M_{p c}} \\
+\frac{2 V_{p C}^{0} c_{\varphi, 2}\left(c_{p, p c} m_{i n}+6 K_{T, S G}\right) T_{P C}}{c_{p, p c} M_{p c}}
\end{array}\right) T_{P C}
\end{aligned}
$$

The state space of pressurizer is

$$
\begin{aligned}
& \left(\begin{array}{c}
d M_{P R} / d t \\
d M_{P C} / d t \\
d T_{P R} / d t
\end{array}\right)= \\
& \left(\begin{array}{ccc}
a & b & c \\
\frac{\varphi\left(T_{p C}\right) V_{p C}^{0}}{M_{P R}} & \frac{\left(m_{\text {in }}-m_{\text {out }}\right)}{M_{P C}}-1 & 0 \\
0 & 0 & \left(X_{m_{P R}>0}-1\right)
\end{array}\right)\left(\begin{array}{c}
M_{P R} \\
M_{P C} \\
T_{P R}
\end{array}\right) \\
& +\left(\begin{array}{ccc}
d & 0 & 0 \\
0 & 0 & 0 \\
\frac{x_{m_{P R}>0} c_{p, P C}}{c_{p, P R}} & \frac{-1}{c_{p, P R} M_{P R}} & \frac{1}{c_{p, P R} M_{P R}}
\end{array}\right)\left(\begin{array}{c}
T_{P C} \\
W_{\text {loss }, P R} \\
W_{\text {heaty }, P R}
\end{array}\right)
\end{aligned}
$$

Such that 


$$
\begin{aligned}
& \mathrm{a}=-\frac{V_{p C}^{0} c_{\varphi, 1}\left(m_{i n} T_{p c, I}-m_{o u t}\right)}{M_{p c} M_{p R}} \\
& \mathrm{~b}=\frac{\left(m_{\text {in }}-m_{o u t}\right)}{M_{p c}} \\
& \mathrm{c}=-\frac{V_{p C}^{0} c_{\varphi, 1}\left(c \Psi+6 K_{T, S G} T_{S G}-W_{\text {loss }, p c}\right)}{c_{p, p c} M_{p c} T_{p R}} \\
& \mathrm{~d}=\left(\frac{V_{p C}^{0} c_{\varphi, 1}\left(c_{p, p c} m_{i n}+6 K_{T, S G}\right)}{c_{p, p c} M_{p c}}-\right. \\
& \frac{2 V_{p C}^{0} c_{\varphi, 2}\left(m_{i n} T_{p c, I}-m_{o u t}\right)}{M_{p c}}- \\
& \frac{2 V_{p C}^{0} c_{\varphi, 2}\left(c \Psi+6 K_{T, S G} T_{S G}-W_{l o s s, p c}\right)}{c_{p, p c} M_{p c}}+ \\
& \left.\frac{2 V_{p C}^{0} c_{\varphi, 2}\left(c_{p, p c} m_{i n}+6 K_{T, S G}\right) T_{P C}}{c_{p, p c} M_{p c}}\right)
\end{aligned}
$$

Where the Output are:

$$
\begin{aligned}
& l_{P R}=\frac{V_{P R}}{A_{P R}} \\
& p_{p R}=p_{*}^{T} T_{P R}
\end{aligned}
$$

Where :

$$
\begin{aligned}
& V_{P R}=V_{P C}-V_{p C}^{0} \text { and } V_{P C}=\frac{M_{P C}}{\varphi\left(T_{P C}\right)} \\
& \left(\begin{array}{c}
l_{P R} \\
p_{p R}
\end{array}\right)=\left(\begin{array}{ccc}
\frac{-V_{p C}^{0}}{M_{P R} A_{P R}} & \frac{1}{\varphi\left(T_{P C}\right) A_{P R}} & 0 \\
0 & 0 & p_{*}^{T}
\end{array}\right)\left(\begin{array}{c}
M_{P R} \\
M_{P C} \\
T_{P R}
\end{array}\right)
\end{aligned}
$$

\section{FUZZY STATE SPACE}

The definition of the FSSM of a multivariable dynamic system [5] is given as follows:

$$
\begin{aligned}
S_{g F:} \quad \dot{x}(t) & =\mathrm{A} \boldsymbol{x}(\mathrm{t})+\mathrm{B} \widetilde{\boldsymbol{u}}(t) \\
\widetilde{y}(t) & =\mathrm{C} \boldsymbol{x}(\mathrm{t})
\end{aligned}
$$

where $\widetilde{\boldsymbol{u}}$ denotes the fuzzified input vector $\left[u_{l}\right.$, $\left.u_{2}, \ldots, u_{n}\right]^{\mathrm{T}}$ and $\tilde{y}$ denotes the fuzzified output vector $\left[y_{1}, y_{2}, \ldots, y_{m}\right]^{\mathrm{T}}$ with initial conditions as $t_{0}=$ 0 and $\boldsymbol{x}_{0}=\boldsymbol{x}\left(t_{0}\right)=0$. The elements of state matrix $A^{p \times p}$, input matrix $\boldsymbol{B}^{p \times n}$ and output matrix $C^{m \times p}$ are known to a specified accuracy.

Let $a_{i}$ be the value in set $I_{i}$ and the fuzzy set $F_{I_{i 1}}$ such that $F_{I_{i 1}} \in I_{i 1}$ be the preferred value for the input $a_{i}$. Here, for $x_{1} \in F_{I_{i 1}}$, the value $F_{I_{i 1}}\left(x_{1}\right)$ represent the degree of occurrence of $x_{1}$ in the value set of $I_{i 1}$.

$S_{g}$ is a performance parameter based on FSSM whereby all input parameter are considered as its variables and can be presented within a fuzzy set $F_{S_{g}}$.

The pressurizer contains three inputs and two outputs that are known as multiple-input multiple-output (MIMO) model. The MIMO model can be split into $m$ equivalent MISO models with all of the $n$ input parameters of the system. However, only one of the $\mathrm{m}$ output parameters being subject to fuzzy modeling [6]. Thus, the pressurizer modeling problem with three inputs and two outputs can be reduced to the development of fuzzy MISO models with three inputs and one output. Hence, $S_{g}: I_{1} \times I_{2} \times I_{3} \times \ldots \times I_{n} \rightarrow R$ is defined as the performance parameter based on the FSSM such that $r=S_{g}\left(a_{1}, a_{2}, a_{3}, \ldots, a_{n}\right)$. The procedures are the implementation of the Fuzzy State Space algorithm into state space equation and Modified Optimized Defuzzified Value Theorem in determine $r^{*}=S_{g}{ }^{*}\left(a_{1}, a_{2}, a_{3}, \ldots, a_{n}\right)_{f^{*}(o p t)}$ [6].

\section{RESULT AND DISCUSSION}

A state space of the pressurizer is fuzzified and solved by using fuzzy state space algorithm [7]. A Matlab programming is constructed by using data obtained from [8]. Fuzzy inputs values for preferred value at $\alpha=1$ and $\alpha=0$ are shown in Table1. Meanwhile fuzzy inputs value with step size of 0.2 for $\alpha$-cuts are shown in Table 2. The outputs induce for pressurizer can be formulated as a linear combination of input variables and given as:

$$
\begin{aligned}
& l_{P R}=0.00752\left(T_{P C}+W_{\text {loss }, P R}+W_{\text {heaty }, P R}\right) \\
& p_{p R}=0.1925\left(T_{P C}+W_{\text {loss }, P R}+W_{\text {heaty }, P R}\right)
\end{aligned}
$$

Table.1 Input Parameter specification

\begin{tabular}{c|ccc}
\hline Input Parameter & 0 & 1 & 0 \\
\hline$T_{P C}$ & 263.0 & 281.1 & 296.1 \\
$W_{\text {loss }, P R}$ & 136.2 & 168.2 & 200.2 \\
$W_{\text {heaty }, P R}$ & 136 & 168 & 200 \\
\hline
\end{tabular}

The desire value and its domain for fuzzy outputs of pressurizer are shown in Table 3. Table 4 shows the domain and desire value for fuzzy induced performance parameter of pressurizer that is obtained by substitute the input parameter into equation (10) and (11).The intersection between fuzzy induced performance and fuzzy preferred output of pressurizer is determined in order to obtain the fuzzy optimal value or $f^{*}$ (see Fig. 2). 
Table.3 Fuzzy Output Performance Parameter

\begin{tabular}{l|ll}
\hline & Domain & Desire Value \\
\hline$l_{P R}$ & $4.6-5.6$ & 4.8 \\
$p_{p R}$ & $119.2-123.5$ & 123 \\
\hline
\end{tabular}

Table.4 Fuzzy Induced Performance Parameter

\begin{tabular}{l|ll}
\hline & Domain & Desire Value \\
\hline$l_{P R}$ & $4.0-5.2$ & 4.6 \\
$p_{p R}$ & $103-134$ & 118.8 \\
\hline
\end{tabular}

Table.2 Fuzzy Input for alpha cut

\begin{tabular}{c|llllll}
\hline & $\alpha$-cuts & & & & \\
\cline { 2 - 7 } Input Parameter & 0.0 & 0.2 & 0.4 & 0.6 & 0.8 & 1.0 \\
\hline$T_{P C}$ & $263.0-296.1$ & $266.6-293.1$ & $270.3-290.1$ & $273.9-287.1$ & $277.5-284.1$ & $281.1-281.1$ \\
$W_{\text {loss }, P R}$ & $136.2-200.2$ & $142.6-193.8$ & $149-187.4$ & $155.4-181$ & $161.8-174.6$ & $168.2-168.2$ \\
$W_{\text {heaty }, P R}$ & $136-200$ & $142.4-193.6$ & $148.8-187.2$ & $155.2-180.8$ & $161.6-174.4$ & $168-168$ \\
\hline
\end{tabular}

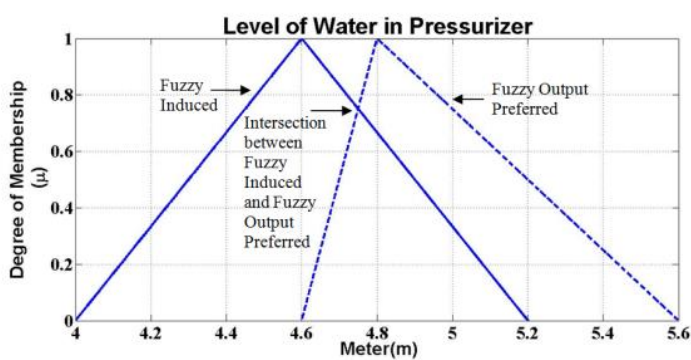

(a)

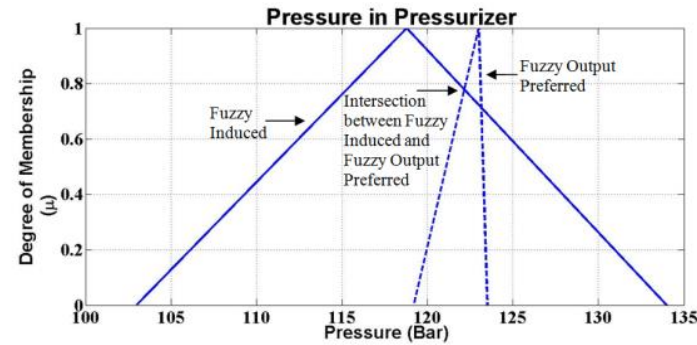

(b)

Figure. 2 Graph of intersection between fuzzy output performance and fuzzy preferred output for:

a) Level of water in Pressurizer

b) Pressure in Pressurizer

The value for $f^{*}=0.7789$ is selected due to as it is the largest fuzzy value. The fuzzy value of $f^{*}$ is used in finding optimal input parameter by using Modified Optimized Defuzzified Value Theorem [6]. Table 5 shows the optimal input for $T_{P C}=284.4^{\circ} \mathrm{C}, \quad W_{\text {loss }, P R}=175.3 \mathrm{~kJ} / \mathrm{s}$ and $W_{\text {heaty }, P R}=175.1 \mathrm{~kW}$ with the percentage errors of $1.17,4.22$ and 4.23 respectively. The output value for calculated are $l_{P R}=4.77 \mathrm{~m}$ and $p_{p R}=$ 122.20 bar with percentage errors 0.63 and 0.63 respectively as shown in Table 6 .

Table.5 Optimal Value for Input Parameter of Pressurizer

\begin{tabular}{|c|l|l|l|}
\hline Input & Calculated & Preferred & $\begin{array}{l}\text { Percentage } \\
\text { Error }(\%)\end{array}$ \\
\hline$T_{P C}$ & 284.4 & 281.1 & 1.17 \\
\hline$W_{\text {loss }, P R}$ & 175.3 & 168.2 & 4.22 \\
\hline$W_{\text {heat }, P R}$ & 175.1 & 168 & 4.23 \\
\hline
\end{tabular}

Table.6 Optimal Value for Output

\begin{tabular}{|c|l|l|l|}
\hline Output & Calculated & Preferred & $\begin{array}{l}\text { Percentage } \\
\text { Error }(\%)\end{array}$ \\
\hline$l_{P R}$ & 4.77 & 4.8 & 0.63 \\
\hline$p_{p R}$ & 122.20 & 123 & 0.65 \\
\hline
\end{tabular}

The value of percentage error is small as given in Table 6. It shows that the accuracy of the fuzzy state space of pressurizer is reliable. Next the optimal input for calculated value in Table 5 is used in Matlab Simulink (see Figure 3). The Simulink model depends as equation (6) to equation (9), and is generated from 0.1 until 100 seconds. The input data have been manipulated to be either decrease or increase in order to define the pattern of output for pressurizer (see Figure 4 and $5)$.

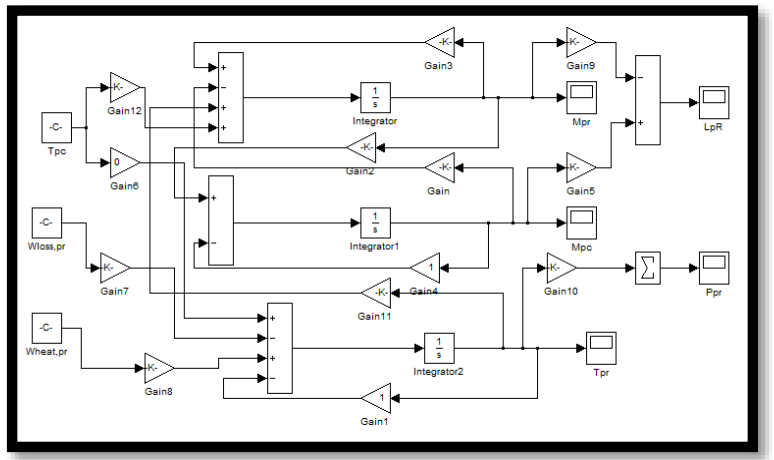

Figure.3 Modeling Fuzzy State Space of Pressurizer 


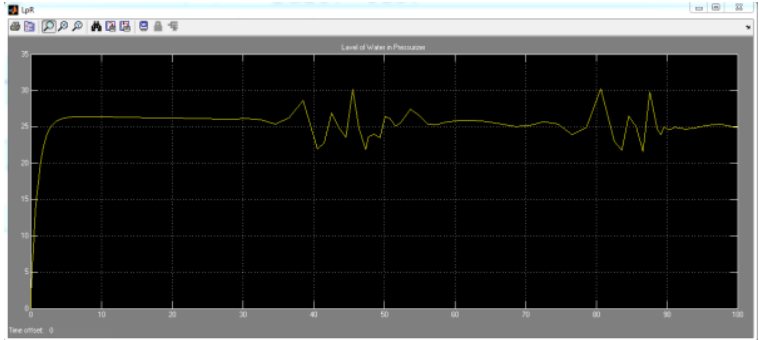

(a)

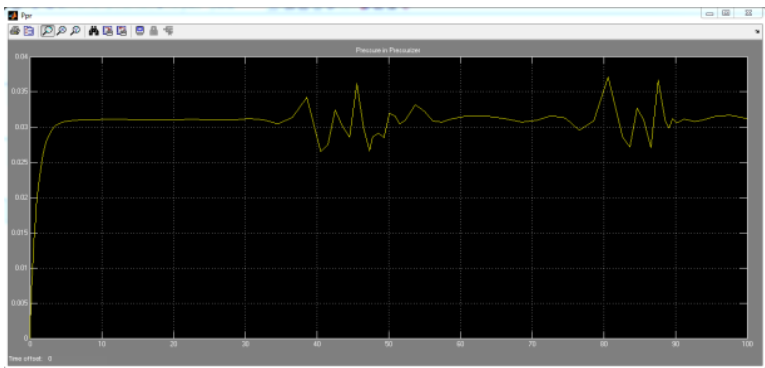

(b)

Figure.4 Graph of output when $T_{P C}$ and $W_{l o s s, P R}$ are decreased for:

a) Level of water in pressurizer versus time

b) Pressure in pressurizer versus time

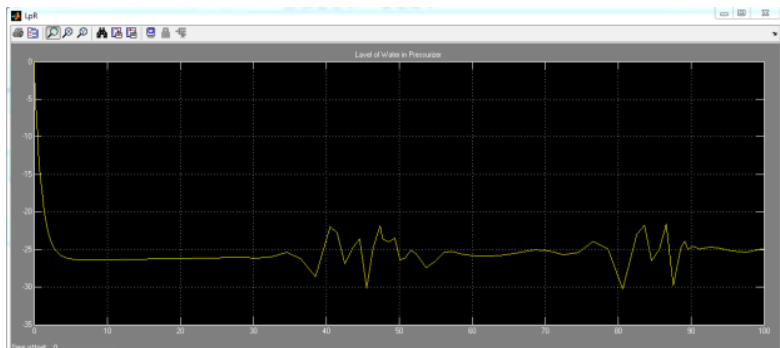

(a)

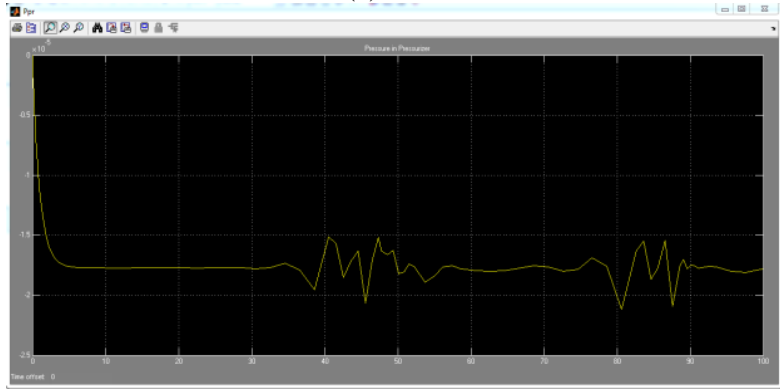

(b)

Figure.5 Graph of output when $T_{P C}$ and $W_{\text {loss }, P R}$ are increased for:

a) Level of water in pressurizer versus time

b) Pressure in pressurizer versus time

Based on Figure 4 and 5, the pattern of graph for level of water and pressure in pressurizer water reactor are in agreement with the assumptions that have mentioned before [9]. If the water level increased, then the pressure is increased. On the other hand, if the level of water decreased, then the pressure is decreased.

Figure 4 shows that when the input for $T_{P C}$ and $W_{\text {loss,PR }}$ are decreased, the level of water and pressure in pressurizer will be increase. It is caused by the increasing of energy, $W_{\text {heaty,PR }}$ whereby reactor coolant system temperature starts too increased [9]. Hence, the level of water increased and the pressure also increased. When the input for $T_{P C}$ and $W_{\text {loss, } P R}$ are increased, the level of water and pressure in pressurizer will start to decrease. It is due to the increasing of heat lost, $W_{\text {loss }, P R}$ whereby reactor coolant temperatures start to decrease. Therefore, the water level and the pressure decreased [9].

\section{CONCLUSION}

The fuzzy state space of pressurizer in a nuclear power plant is successfully defined. The results from fuzzy state space algorithm show that the percentage error for the input and output is small. The simulation shows that if the water level increased, then the pressure increased. On the other hand, if the water levels decrease, then the pressure is decrease.

\section{ACKNOWLEDGMENTS}

This work has been supported by Ibnu Sina Institute, MyBrain15 scholarship from Ministry of Education Malaysia and University Teknologi Malaysia.

\section{REFERENCES}

[1] Li, H. et al.,( 2010). Progress in Nuclear Energy A new formula of neutron multiplication during startup of PWR. Progress in Nuclear Energy, 52(4), pp.321326

[2] Manual, Reactor Concepts. "Rev. 0200." United States Nuclear Regulatory Commission Technical Training Center, NRC ADAMS Accession Number ML023020519.

[3] Gábor, A., Hangos, K., Szederkényi, G., September 2010. Modeling and identification of the pressurizer of a VVER nuclear reactor for controller design purposes. In: 11th International $\mathrm{PhD}$ Workshop on Systems and Control.

[4] Attila Gábor, Ilona Sonnevend, Tamás Bartha, (2011). Control-oriented modelling of the primary circuit and its controllers of a PWR nuclear power plant. MTA SZTAKI.

[5] R. Ismail, T. Ahmad, S. Ahmad \& R.S Ahmad, "On The Properties of Multi-Connected System Of Fuzzy State Space Model" . Proc. The $2^{\text {nd }}$. International Conference on Research and Education in Mathematics (ICREM 2), Institute of Mathematical Research, Universiti Putra Malaysia, 43400 Serdang, 25-27 May 2005.

[6] Izaz Ullah Khan,Tahir Ahmad and Normah Maan, Feedback Fuzzy State Space Modeling and Optimal Production Planning for Steam Turbine of a Combined Cycle Power Generation, Research Journal of Applied Sciences 7, 100-107 (2012).

[7] Ismail, Razidah, and Noor Ainy Harish. "A Fuzzy Algorithm for Parameter Estimation of a Superheater System.", Fuzzy Theory and Applications (2008) .

[8] Cs. Fazekas, G. Szederkényi and K.M. Hangos, Nuclear Engineering and Design 237, 1071-1087 (2007).

[9] Oka, Yoshiaki, and Katsuo Suzuki. Nuclear Reactor Kinetics and Plant Control. Springer, 2013. 